\title{
Oroantral Communication Repair Using Platelet-Rich Fibrin
}

\author{
Chenchev $\mathrm{Iv}^{1}$, Neichev $\mathrm{D}^{1}$, Atanasov $\mathrm{D}^{1}$, Dobreva $\mathrm{D}^{1}$ \\ ${ }^{1}$ (Department Of Oral Surgery, Faculty Of Dental Medicine, Medical University - Plovdiv, Bulgaria)
}

\begin{abstract}
Purpose: The purpose of this study is to check up the possible usage of a new approach when treating oroantral communication $(O A C)$ which includes the usage of platelet-rich fibrin (PRF).

Methods and materials: 6 patients $(4$ women and 2 men) participated in this study with oroantral communications after the extractions of maxillary molars. The OAC was closed surgically using PRF membranes. The clinical results were monitored over the course of 14 days with the aid of the Clinical Healing Score (CHS), and the subjective results were measured using the standard Visual Analog Scale (VAS).

Results: For all treated patients in this study we achieved a complete closure of the OAC with no early or later complications and minimal discomfort. The average results based on the VAS were $2 \mathrm{~cm}$.

Conclusions: Our method for treating OAC with the aid of PRF in this limited in size study showed some excellent results.
\end{abstract}

Keywords: oroantral communication, platelet-rich fibrin, oral surgery

\section{Introduction}

Oroantral communication $(\mathrm{OAC})$ is the condition where there is a pathological communication between the oral cavity and the maxillary sinus. The maxillary sinus forms a large part of the maxilla and normally includes a part of the distal alveolar process. OAC commonly appears after the extraction of maxillary premolars and molars. ${ }^{[1,2]}$ The reasons are: anatomical features, pathological processes affecting the apical area of the teeth and improper work of the dental practitioner ${ }^{[3]}$. The average frequency of OAC after the extraction of a tooth is not big and is within the range of about $5 \%$ of all extracted teeth. ${ }^{[4,5]} \mathrm{An}$ OAC can be closed spontaneously if it is small, with a size of less than $3 \mathrm{~mm} \cdot{ }^{[1,6]}$ However, most authors suggest that OAC is treated soon for the prophylaxis of the formation of the oroantral fistula, the developed chronic inflammation of the maxillary sinus and the guarantee of a better treatment result ${ }^{[7,8]}$. The closure of the $\mathrm{OAC}$ is commonly done with a surgical procedure. In the cases of small perforations $(<3 \mathrm{~mm})$ the treatment is achieved by tightly stitching the extraction wound if possible. Otherwise if adequate stitching is not possible then a plastic closure is done ${ }^{[9]}$. Plastic procedures can include vestibular or palatinal access, ${ }^{[3]}$ and according to Awang $\mathrm{MN}^{[10]}$ they can be classified as procedures with local flaps or distal flaps. The most commonly used techniques are the ones with vestibular advanced flap (Rehrmann) ${ }^{[11]}$ and sometimes palatinal flaps (palatal rotation-advancement flap) ${ }^{[12,13]}$ or plastic techniques with the buccal fat pad (Môczair) ${ }^{[9,14]}$. Apart from the classic procedures treating $\mathrm{OAC}$ there are others that aim not only to close the OAC but to conserve the bone tissues of the maxillary sinus floor. This allows for the later usage of dental implants. ${ }^{[15]}$ These techniques use autogenous bone and a variety of bone substitute materials alone or in combination with isolating membranes (sandwich graft technique, GTR ${ }^{[15,16]}$. El Shourbagy MH et al. ${ }^{[17]}$ close OACs of 8 patients using bone substitute material (Fisiograft) and PRF membrane achieving good results. It is known that PRF can stitch and repair the rapidly torn sinus mucosa. ${ }^{[18-22]}$ Platelet-rich fibrin (PRF) is defined as an autogenous solid biomaterial, containing increased amount of leukocytes and platelets. ${ }^{[23,24]} \mathrm{PRF}$ is used as a stimulating factor of the bone and soft tissue regeneration in dental implantology and periodontal surgery. ${ }^{[25]}$ It is used for the healing of extraction wounds,${ }^{[26]}$ treatment of interosseous defects, ${ }^{[27]}$ radicular cysts, ${ }^{[28]}$ influencing the jaw bones in the case of biophosphonate osteonecrosis, ${ }^{[29]}$ etc. Based on the literature data ${ }^{[30-33]}$ and our clinical experience with the biopotential of PRF ${ }^{[34-36]}$ we set out to test the possibilities of using PRF in the treatment of maxillary sinus perforations.

\section{Materials and Method}

\subsection{Patients}

The study was conducted on a total of 6 patients ( 4 women and 2 men) with OAC greater than $3 \mathrm{~mm}$ formed after the extraction of maxillary molars. For two of the patients the closure was done 48 hours after the extraction, while for the rest - just after it was diagnosed. All patients were treated surgically at the Department of Oral Surgery in the Faculty of Dental Medicine - Plovdiv. 


\subsection{Clinical examination}

After extraction the presence of OAC is determined by asking the patient to exhale gently through his nose while his nostrils are pinched (Valsalva test). If necessary, patients were examined clinically to assess the OAC by propping it with a blunt prop (small curette) - Fig. 1.

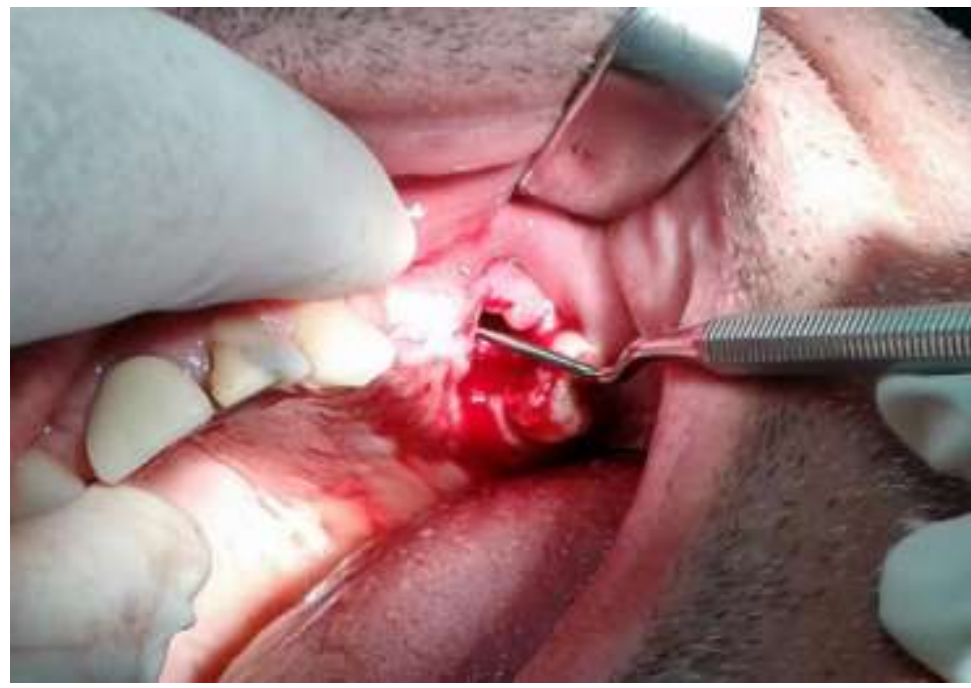

Fig. 1 - Presence of oroantral communication in the area of tooth 26

\subsection{Preparation of the PRF membrane}

The PRF clot is prepared following the method of Choukroun $\mathrm{J}$ et al. ${ }^{[6]}$ After the venipuncture of $\mathrm{v}$. cubity with a $10 \mathrm{ml}$ vacuum test-tube (Advanced-PRFTM), $9 \mathrm{ml}$ of blood is taken from the patient. The blood is then immediately put into a PRF DUO (Processfor PRF®-France) centrifuge for 8 minutes at 1300 RPM. The resulting PRF clot is put back into a test-tube using a long, straight anatomical tweezers and then by using surgical scissors or scalpel it is separated from the red part (erythrocytes). The PRF membrane, in our methodolog $y^{[34-36]}$, is formed out of two PRF clots (Fig.2a) by putting them on top of one another - The areas bordering with the red part are put at the opposite ends (Fig.2b) and it is then dried in a special for this case box A-PRF Box®- Fig.2c
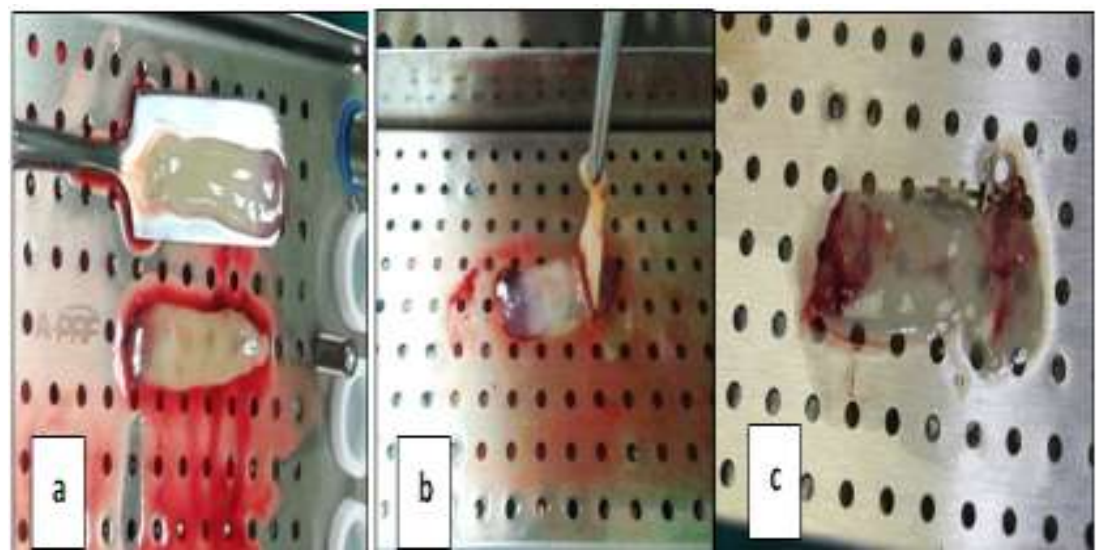

Fig.2 - Stages of the preparation of PRFm

\subsection{Surgical treatment}

Surgical treatment is only done if clinical or diagnostic data for acute inflammatory process in the area of the affected sinus is not present. If necessary an additional local anesthesia is used in the area of the extracted tooth and the OAC. The extraction wound is carefully disinfected and dried with sterile lint. The alveolus is densely filled with the PRF membranes, made out of the patient's own blood - Fig. 3. 


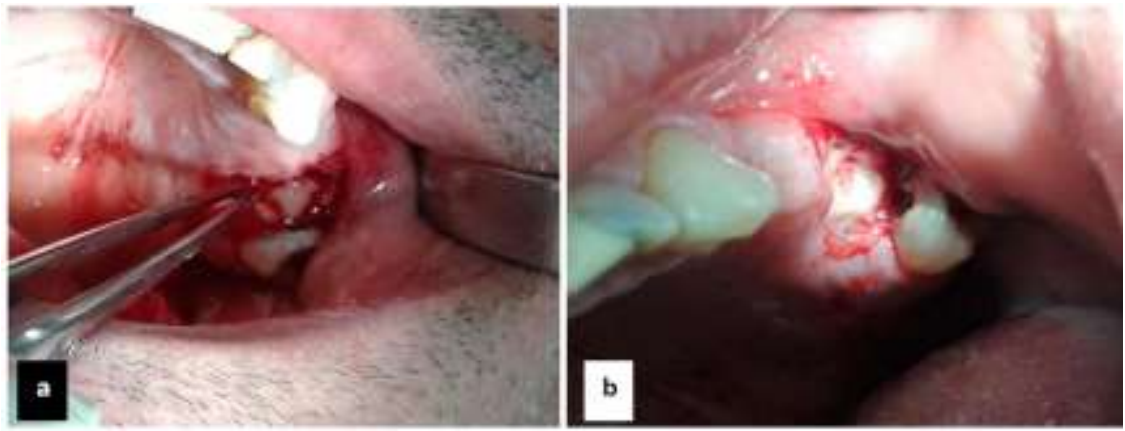

Fig.3 - $\square$ )Filling the alveolus with the PRF membrane b) Filled with a PRF membrane alveolus

The edges of the alveolus are stitched with a simple interrupted suture or eight-like suture using absorbable or non-absorbable thread 000 - Fig. 4.

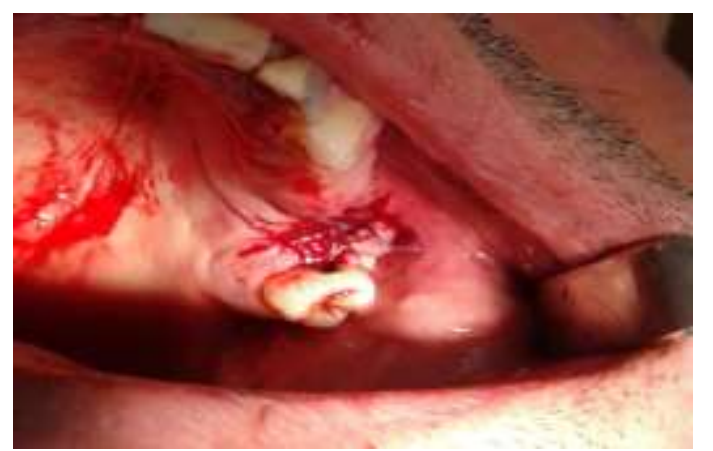

Fig.4 - Alveolus sutured with simple interrupted suture

\subsection{Clinical and subjective measurements}

Clinical measurement of the wound healing was done using the 5-score Clinical Healing Score (CHS) ${ }^{[37]}$ The sum of 5 criteria is the healing score. A healing score of 0 indicates better healing and vice versa. The results of the CHS were measured on the $24^{\text {th }}$ hour and the $7^{\text {th }}$ and $14^{\text {th }}$ day after the treatment. The subjective rating for the level of postoperative pain was done with the aid of the Visual Analog Scale (VAS) on the $24^{\text {th }}$ hour and 14 days after. Absence of pain was considered to be $0 \mathrm{~cm}$, while the strongest pain $-10 \mathrm{~cm}$. The average values for all parameters were calculated for the resulting data from the clinical and subjective studies.

\subsection{Postoperative care}

Patients were assigned a variety of antibiotics for 5-7 days and NSAIDs for the first 3 days. Check-up visits were assigned for the $1^{\text {st }}, 7^{\text {th }}$ and $14^{\text {th }}$ day after the surgery. Instructions were given about a normal diet, postoperative care and oral hygiene of the patient.

\section{Results}

The average values for the clinical results were determined using the Clinical Healing Score. On the $24^{\text {th }}$ hour after the treatment they were 1 and on the $7^{\text {th }}$ and $24^{\text {th }}$ day after they were 0 (complete epithelization of the wound) - Table 1. The average value for the subjective evaluation of the patients' pain 24 hours after the surgery was determined using the VAS and was about $2 \mathrm{~cm}$.

Table 1 - Clinical Healing Score (Sum of 5 criteria) - average values

\begin{tabular}{|l|c|c|c|c|}
\hline Criteria & Score & 24 hour & 7day & 14day \\
\hline Redness absent & 0 & 1 & 0 & 0 \\
Redness present & 1 & & & 0 \\
\hline Edema absent & 0 & 1 & 0 & 0 \\
Edema present & 0 & 1 & 0 & 0 \\
\hline Healthy granulation tissue present & 1 & & & 0 \\
Healthy granulation tissue absent & 0 & 1 & 0 \\
\hline Signs of epithelization present & 1 & & & 0 \\
Signs of epithelization absent & & & \\
\hline
\end{tabular}

Note - The sum of 5 criteria is the clinical healing score; when the score is 0 the healing is better and vice versa. 


\section{Discussion}

For all patients in this study we achieved a closure of the OAC while the postoperative period passed without complications and minimal complaints. Using PRF aids the quick healing of the soft and hard tissues which can also be seen when using it in the treatment of other conditions in the oral surgery. ${ }^{[22,25-27,30,34,36]}$ The absence of postoperative complications is due to the biological qualities of the PRF to influence the local inflammation of the wound ${ }^{[2,34,35,37,38]}$ The minimal discomfort for the patients is probably due to the fact that on the one hand, in our method for treating OAC no additional tissues are dissected, which prevents other possible traumas. On the other hand the minimal amount of complaints and postoperative pain are due to the PRF. This is confirmed by the results presented in other studies using PRF when treating surgically different nosological units. ${ }^{[39-41]}$ The method used in this study for the closure of OAC allows for the treatment to proceed immediately after its diagnose. This prevents the formation of oroantral fistula, the development of chronic inflammation of the maxillary sinus and leads to a better treatment. ${ }^{[7,8]}$ In the available literature we found no data for the usage of PRF as an independent grafting material in the treatment of maxillary sinus perforations after teeth extraction. This does not allow us to compare our results with those of other studies. Some advantages of the presented method in this study for the closure of OAC with the aid of PRF are: it is easy to conduct; no other resources, time or qualified personnel are needed; and last but not least PRF is readily accessible in ambulatory conditions and is a relatively cheap autogenous biomaterial.

\section{Conclusion}

Based on this limited in size study we can conclude that this method of treating OAC using PRF membranes is a good alternative. The final results displayed a minimal postoperative discomfort for the patients and a quick epithelization of the alveolus (OAC) over a period of 7 days. Larger in scale studies are necessary in order to further confirm and test the possibilities of this method used to treat OAC with the aid of PRF.

\section{References}

[1]. Abuabara A, Cortez A.L.V., Passeri L.A., Moraes de M., Moreira R.W.F. evaluation of different treatments for oroantral/oronasal communications. Int J Oral Maxillofac Surg 2006 Feb;35(2):155-8.

[2]. Punwutikorn J, Waikakul A, Pairuchvej V. Clinically significant oroantral communications - a study of incidence and site. Int J Oral Maxillofac Surg 1994;23(1):19-21.

[3]. Atanasov D. (Editor) Oral surgery. Tafprint. Plovdiv. 2011: 244-245.

[4]. del Rey-Santamaria M, Valmaseda CE, Berini AL, Gay EC. Incidence of oral sinus communications in 389 upper thirmolar extraction. Med Oral Patol Oral Cir Bucal 2006;11(4):334-338.

[5]. Bodner L, Gatot A, Bar-Ziv J. Technical note: oroantral fistula: improved imaging with a dental computed tomography software program. Br J Radiol 1995;68(815):1249-50.

[6]. von Wowern N. Correlation between the development of an orantral fistula and the size of the corresponding bony defect. J Oral Surg 1973;31(2):98-102.

[7]. Visscher SH, van Minnen B, Bos RRM. Closure of oroantral communications: a review of the literature. J Oral Maxillofac Surg 2010;68:1384-91.

[8]. Vasscher SH, van Minnen B, Boss R. Closure of oroantral communications: a review of the literature. J Oral Maxillofac Surg. 2010; 68(6): 1384-1391.

[9]. Ehrl PA. OAC, epicritical study of 175 patients, with special concern to the secondary operative closure. Int J Oral Surg 1980; 9: 351-5.

[10]. Awang MN. Closure of oroantral fistula. Int J Oral Maxillofac Surg 1988;17(2):110-5.

[11]. Rehrmann A. A method of closure of oroantral perforation. Dtsch Zahnarztl Z. 1936;39:1136-9.

[12]. Abuabara A, Cortez A.L.V., Passeri L.A., Moraes de M., Moreira R.W.F. evaluation of different treatments for oroantral/oronasal communications. Int J Oral Maxillofac Surg 2006 Feb;35(2):155-8.

[13]. Ribeiro LP, Toledo CT, Aleixo MR, Durigan MC et al. Treatment of Oroantral Communication Using the Lateral Palatal Sliding Flap Technique. Case Reports in Medicine.Volume 2015, Article ID 730623, 5 pages

[14]. Môczair L. A new surgical method of closure of oroantral fistula of odontogenic origin. Stomatol (Roma). 1930;28:1087-8.

[15]. Vasscher SH, van Minnen B, Boss R. Closure of oroantral communications: a review of the literature. J Oral Maxillofac Surg. 2010; 68(6): 1384-1391

[16]. A. Scattarella, A. Ballini, F. R. Grassi et al., "Treatment of oroantral fistula with autologous bone graft and application of a

[17]. non-reabsorbable membrane," International Journal of Medical Sciences. 2010; 7 (5): 267-271.

[18]. El Shourbagy MH, Hussein MM, Khedr MS, Abd Elal S. Oroantral communication repair using bone substitute and platelets rich fibrin. Tanta Dental Journal 2015; 12: 65-70.

[19]. Simonpieri A, Choukroun J, Del Corso M, Sammartino G, Dohan Ehrenfest D M. Simultaneous Sinus-Lift and Implantation Using Microthreaded Implants and Leukocyte- and Platelet-Rich Fibrin as Sole Grafting Material: A Six-Year Experience. Implaqnt Dentistry. 2011; 20 (1): 3 -12.

[20]. Baykul T, Findik Y. Maxillary sinus perforation with presence of an antral pseudocyst, repaired with platelet rich fibrin. Ann Maxillofac Surg. 2014; 4(2): 205-207.

[21]. Diss A, Dohan DM, Mouhyi J, et al.Osteotome sinus floor elevation using Choukroun's platelet-rich fibrin as grafting material: A 1-year prospective pilot study with microthreaded implants. Oral Sur Oral Med Oral Pathol Oral Radiol Endod. 2008;105: 572-579.

[22]. Choukroun J, Diss A, Simonpieri A, Girald M et al. Platelet-rich fibrin (PRF): a second-generation platelet concentrate. Part V: Histologic elevation of PRF effect on bone allograft maturation in sinus lift. Oral Surg Oral Med Oral Pathol Oral Radiol Endod 2006; 101: 299-303.

[23]. Saluja H, Dehane V, Mahindra U. Platelet -Rich Fibrin - A second generation platelet concentrate and a new friend and maxillofacial surgeons. Anals of Maxillofacial Surgery. 2011; 1(1): 53-57. 
[24]. Dohan DM, Choukroun J, Diss A et al. Platelet-rich fibrin (PRF): a second-generation platelet concentrate-part II: platelet-related biologic features. Oral Sur Oral Med Oral Pathol Oral Radiol Endod. 2006; 101 (3): 45-50.

[25]. Dohan DM, Choukroun J, Diss A, Dohan SL, Dohan AJ, Mouhyi J, et al. Platelet-rich fibrin (PRF): a secondgeneration platelet concentrate. Part III: leucocyte activation: a new feature for platelet concentrates? Oral Surg Oral Med Oral Pathol Oral RadiolEndod. 2006 Mar;101(3): 51-5.

[26]. Toffler M, Toscano N, Holtzclaw D, Del Corso et al. Introducing Choukroun's Platelet Rich Fibrin (PRF) to the Reconstructive Surgery Milieu. The Journal Implant Adv Clin Dent.2009; 1: 21-30.

[27]. Zhao JH, Tsai $\mathrm{CH}$, Chang YC. Clinical and histologic evaluations of healing in an extraction socket filled with platelet-rich fibrin. $\mathrm{J}$ Dent Sci. 2011 Jun;6(2):116-122.

[28]. Chang YC, Wu KC, Zhao JH.Clinical application of platelet-rich fibrin as the sole grafting material in periodontal intrabony defects. J Dent Sci. 2011 Sep;6(3):181-188.

[29]. Zhao JH, Tsai CH, Chang YC. Management of radicular cysts using platelet-rich fibrin and bioactive glass: a report of two cases. J Formos Med Assoc. 2014 Jul;113(7): 470-6.

[30]. Mozzati M, Gallesio G, Arata V, Scoletta M. Plateletet-rich fibrin therapies in the treatment of intrawenous bisphosphonate-related osteonecrosis of the jaw: a report of 32 cases. Oral Oncol.2012; 48(5): 469-74.

[31]. Choukroun J, Diss A, Simonpieri A, Girald M et al. Platelet-rich fibrin (PRF): a second-generation platelet concentrate. Part V: Histologic elevation of PRF effect on bone allograft maturation in sinus lift. Oral Surg Oral Med Oral Pathol Oral Radiol Endod 2006; 101: 299-303.

[32]. Toffler M, Toscano N, Holtzclaw D. Osteotome - Mediated Sinus Floor Elevation Using Only Platelet-Rich Fibrin: An Early Report on 110 Patients. Implant Dentistry. 2010; 19 (5): 447-456.

[33]. Saluja H, Dehane V, Mahindra U. Platelet-Rich fibrin: A second generation platelet concentrate and a new friend of oral and maxillofacial surgeons. Ann Maxillofac Surg. 2011

[34]. Borie E, Oliví DG, Orsi IA, Garlet K et al. Platelet -Rich Fibrin in dentistry: a literature review. Int J Clin Exp Med. 2015; 8 (5): 79922-29.

[35]. Chenchev I, Atanasov D, Vicheva D. The treatment of gingival recessions - Our experience. Romanian Journal of Rhinology. 2016; 6 (22): 85-91.

[36]. Chenchev Iv, Neichev D, Vicheva D, Atanasov D, Noncheva V. Vista technique and Platelet-Rich Fibrin Membrane for Treatment of Multiple Adjacent Gingival Recessions - 6 month follow-up. IOSR Journal of Dental and Medical Sciences. 2016; 15, 7 (5): 128133 .

[37]. Chenchev I, Cholakova R. Treatment of Oral Mucosal Lesions by Scalpel Excision and Platelet-Rich Fibrin Membrane Grafting: A case report. Journal of IMAB. 2016 Jul-Sep; 22 (3): 1212-1216.

[38]. Choukroun J et al. Platelet-rich fibrin (PRF): a second-generation platelet concentrate. Part IV: clinical effects on tissue healing. Oral Surg Oral Med Oral Pathol Oral Radiol Endod 2006; 101: 56-60.

[39]. Jiing-Huei Zhao, Chung-Hung Tsai, Yu-Chao Chang. Clinical and histologic evaluations of healing in an extraction socket filled with platelet-rich fibrin. Journal of Dental Sciences 2011; 6(2): 116-122.

[40]. Josepha VR, Raghunatha A, Sharmab N. Clinical effectiveness of autologous platelet rich fibrin in the management of infrabony periodontal defects. Singapore Dental Journal. 2012; 33: 5-12.

[41]. Eldibany RM. Platelet rich fibrin versus Hemcon dental dressing following dental extraction in patients under anticoagulant therapy. Tanta Dental Journal. 2014; 11: 75-84.

[42]. Chenchev Iv, Atanasov D, Vicheva D, Noncheva V. Comparative Evaluation of the Subjective Results from the Treatment of Gingival Recessions with Connective Tissue Graft and Platelet Rich Fibrin Membrane. IOSR Journal of Dental and Medical Sciences (IOSR-JDMS). 2016; 15, 5 (5): 73-78. 